\title{
Crosslinked Thermoelectric Hydro-Ionogels: A new class of highly conductive thermoelectric
} materials

Imran Haider Sajid ${ }^{1}$, Mohd Faizul Mohd Sabri ${ }^{*}$, Suhana Mohd Said ${ }^{2}$, Mohd Faiz Mohd Salleh ${ }^{2}$, Nik Nazri Nik Ghazali ${ }^{1}$, R.Saidur ${ }^{3,4}$ Balamurugan Subramaniam² ${ }^{2}$, Syed Waqar Hasan ${ }^{2}$, Hasan Abbas Jaffery ${ }^{1}$

${ }^{1}$ Department of Mechanical Engineering, Faculty of Engineering, University of Malaya, 50603 Kuala Lumpur, MALAYSIA

${ }^{2}$ Department of Electrical Engineering, Faculty of Engineering, University of Malaya, 50603 Kuala Lumpur, MALAYSIA

${ }^{3}$ Research Centre for Nano-Materials and Energy Technology (RCNMET), School of Science and Technology, Sunway University, Bandar Sunway, Petaling Jaya, 47500, Selangor Darul Ehsan, Malaysia.

${ }^{4}$ Department of Engineering, Lancaster University, LA1 4YW, United Kingdom.

*Correspondence should be addressed to Mohd Faizul Mohd Sabri (email: faizul@um.edu.my)

\section{Abstract}

In this work, a new class of highly-conductive chemically cross-linked gel has been synthesized by the confinement of water and IL N, N, N triethyl octyl ammonium bromide $\left(\left[\mathrm{N}_{2228}\right] \mathrm{Br}\right)$ in polyethylene glycol dimethacrylate (PEGDMA) matrix, using in situ thermally initiated radical polymerization loaded with 1 wt. \% free radical initiator azobisisobutyronitrile (AIBN). This novel gel was named as hydroionogel (HIG). The thermoelectric properties of HIG such as ionic conductivity, Seebeck coefficient, and thermal conductivity were measured and owing to its high thermoelectric performance, we referred to this as crosslinked thermoelectric hydro-ionogel, henceforth will be denoted by X-TEHIG. For all the measurements, coin cells were fabricated using commercial LIR 2032 stainless steel battery casings with $\mathrm{X}$-TEHIG sandwiched between the two graphene electrodes. The ionic conductivity of X-TEHIG was examined via AC impedance spectroscopy technique by using a Gamry apparatus. Remarkably, the ionic conductivity of X-TEHIG was higher than that of neat $\left[\mathrm{N}_{2228}\right] \mathrm{Br}$. A linear increase in ionic conductivity of X-TEHIG as a function of temperature was recorded that showed a considerably higher value of 74 $\mathrm{mScm}^{-1}$ at $70{ }^{\circ} \mathrm{C}$. The origin of this high conductivity is attributed to interactions between PEGDMA monomers and cations and anions of the IL and formation of hydrogen bonds between water and $\mathrm{Br}^{-}$ anion, O-H...Br- X-TEHIG demonstrated a higher Seebeck coefficient of $1.38 \mathrm{mVK}^{-1}$. The Fourier transform infrared (FTIR) spectroscopy results revealed the successful polymerization of X-TEHIG by the disappearance of $\mathrm{C}=\mathrm{C}$ peak of methacrylate group in the spectrum of PEGDMA. These results suggest that X-TEHIG may be a potential candidate for thermoelectric applications owing to their high values of ionic conductivity and Seebeck coefficient.

Keywords: Crosslinked thermoelectric hydro-ionogel, thermal conductivity, ionic conductivity, Seebeck coefficient, cyclic voltammetry, FTIR spectroscopy. 


\section{Nomenclature}

S Seebeck Coefficient, VK $^{-1}$

$\sigma \quad$ Electrical conductivity, $\mathrm{Scm}^{-1}$

$\mathrm{K} \quad$ Thermal Conductivity, $\mathrm{Wm}^{-1} \mathrm{~K}^{-1}$

$\mathrm{T} \quad$ Temperature, $\mathrm{K}$

A Area, $\mathrm{m}^{2}$
ZT

PEGDMA

$\mathrm{BMIMBF}_{4}$

AIBN

X-TEHIG
Figure of merit

Polyethylene glycol dimethacrylate

Butyl methyl imidazolium tetrafluoroboarate

Azobisisobutyronitrile

Cross-linked thermoelectric hydroionogel

\section{Introduction}

Production of clean and sustainable energy is of utmost importance for the development of human society. Around $60 \%$ of the fossil fuels energy is lost as waste heat. In order to add a useful contribution in powering to our modern society, various technologies are being explored beyond the use of heat engines. Thermoelectric (TE) modules are one of these approaches $[1,2]$. TE modules convert waste heat directly into electricity with many advantages over conventional heat engines such as they have no moving parts, require no working fluids or gases, highly reliable and eco-friendly [3-5]. The performance of thermoelectric (TE) materials can be evaluated by the dimensionless figure of merit denoted by ZT.

$$
Z T=\left(S^{2} \sigma T\right) / K
$$

where $Z T$ is figure of merit, $S$ is Seebeck coefficient also called thermopower $\left(\mathrm{VK}^{-1}\right), \sigma$ is electrical conductivity $\left(\mathrm{S} \mathrm{m}^{-1}\right), K$ is thermal conductivity $\left(\mathrm{W} /(\mathrm{m} \mathrm{K}), T\right.$ is absolute temperature $(\mathrm{K})$ and $\mathrm{S}^{2} \sigma$ is called power factor $\left(\mathrm{Wm}^{-1} \mathrm{~K}^{-2}\right)$. In order to get high ZT, the materials must possess higher Seebeck coefficient and electrical conductivity along with lower thermal conductivity [6-9]. The higher values of Seebeck coefficient will be accompanied by high voltage output, high electrical conductivity will reduce the Joule heating, and lower thermal conductivity will maintain large temperature gradients in TE modules [10, 11]. In the thermoelectric materials, there is a general trade-off between the Seebeck coefficient and electrical conductivity. With the increase in carrier concentration of TE material, electrical conductivity increases and Seebeck coefficient decreases [6].

In the past, mostly the researchers gave greater emphasis to inorganic conductors and semiconductors as TE materials, for example, $\mathrm{Bi}_{2} \mathrm{Te}_{3} \mathrm{CoSb}_{3}, \mathrm{Mg}_{2} \mathrm{Si}, \mathrm{PbTe}$, and their alloys. Calero et al. prepared the $\mathrm{Bi}_{2} \mathrm{Te}_{3^{-}}$ y $\mathrm{Se}_{\mathrm{y}}$ electrodeposited thin films and achieved a Seebeck coefficient of $120 \mu \mathrm{VK}^{-1}$ for as-deposited films [12]. A Seebeck coefficient of $138 \mu \mathrm{VK}^{-1}$ has been reported by Danine et al. for P-type Bi-Sb-Te $60 \mathrm{~nm}$ nanowire [13]. Besides the low value of Seebeck coefficient of the order of $\mu \mathrm{VK}^{-1}$, several other problems are associated with above-mentioned materials such as toxicity, high manufacturing cost, and paucity of materials that have thus limited their widespread use [7, 14, 15]. Organic conducting polymers have emerged as efficient alternative TE materials because of their low cost, easy to manufacture, lightweight, flexible and low value of intrinsic thermal conductivity. One of the major problems related to them like inorganic conductors and semiconductors is their low value of the Seebeck coefficient as a result of doping [7, 16]. Because of doping their Fermi level is pushed towards the conduction band resulting in a decrease in average transport energy of charge carriers which in turn reduces the Seebeck coefficient [17]. So far the highest ZT of 0.42 has been reported by Kim et al. with a Seebeck coefficient 
of $33.4 \mu \mathrm{VK}^{-1}$ for solution processable conducting polymers. Likewise, Cho et al. published a Seebeck coefficient of $120 \mu \mathrm{VK}^{-1}$ for organic conducting polymers [18, 19]. The low efficiency of organic thermoelectric devices because of relatively small Seebeck coefficient has not been improved despite tremendous research efforts in recent years.

These limitations have motivated researchers' interest in alternative thermoelectric materials. Ionic liquids (ILs) demonstrated significantly higher Seebeck coefficient of the order of $\mathrm{mVK}^{-1}$. They are non-volatile molten salts characterized by high ionic conductivities, low vapor pressure, high Seebeck coefficient and good chemical and electrochemical stability. The ionic conductivity of ionic liquids can be further improved up to 1-2 orders of magnitude with the addition of water [20]. Anouti et al. observed the ionic conductivity $\left(8.23 \mathrm{mScm}^{-1}\right)$ of protic ionic liquid, pyrrolidinium trifluoroacetate, [Pyrr][CF3COO] ${ }^{-}$with 3 wt. $\%$ of water and with the addition of $51 \mathrm{wt.}$. $\%$ of water ionic conductivity increased to $44.20 \mathrm{mScm}^{-1}$ [21]. Migita et al. studied a mixture of ionic liquid, [C4mpyr]- [NTf2] plus [ $\mathrm{Fe}(\mathrm{CN}) 6] 3 /[\mathrm{Fe}(\mathrm{CN}) 6]$ redox couple with metal complexes $\left(\mathrm{Fe}, \mathrm{Cr}\right.$ ) and demonstrated a Seebeck coefficient of $1.49 \mathrm{mVK}^{-1}$. Abraham et al. has reported the Seebeck coefficient of the $\mathrm{I}^{\prime} / \mathrm{I}_{3}{ }^{-}$redox couple in a series of ILs from 0.03 to 0.26 $\mathrm{mVK}^{-1}$ and variation in the value was linked with the nature of both the cation and anion [22]. Recently, Laux et al. studied a series of ILs in LiI// $\mathrm{I}_{2}$ redox couple and achieved highest Seebeck coefficient of 0.3 $\mathrm{mVK}^{-1}$ [23]. Although, the aforementioned examples demonstrated Seebeck coefficient of the order of $\mathrm{mVK}^{-1}$ yet their liquid state limits their uses because of leakage problems and liquid phase electrolyte hinders the devices to work in different positions e.g. upside-down or tilted at large angles [24]. Furthermore, large scale integration and packaging of solid state devices are quite easy [25]. The best option to fully leverage all benefits of ILs is their immobilization into polymer matrices to form ionogels. They will preserve all the attributes of ILs except outflow [26, 27]. Ionogels possess high ionic conductivities and highly tunable properties which render them a popular topic of materials science research in recent years. The ionic conductivity of ionogels is primarily dependent by the amount of uptake of electrolyte solutions (such as ionic liquids) by the polymer matrix. Because of its high retention capability of ionic liquids we used polyethylene glycol dimethacryalte in order to achieve the maximum possible ionic conductivity of ionogels [28]. The ionogels have many industrial applications for example, in lithium-ion batteries, fuel cells, electrochromic materials, dye-sensitized solar cells (DSSCs) for solar energy conversion, electrochemical double layer capacitors (EDLCs), and actuators [29-34]. Moreover, applications of ionogels as thermoelectric materials have never been listed in several review reports published on applications of ionogels [35-38].

In this work, for the first time, we have prepared novel cross-linked thermoelectric hydro-ionogel (XTEHIG) by thermally initiated polymerization/chemical cross-linking of bi-functional monomers of PEGDMA in presence of IL [ $\left.\mathrm{N}_{2228}\right] \mathrm{Br}$ using radical initiator AIBN. Chemically cross-linked gels are thermally stable up to decompositions temperature and show better dimensional stability [39]. Chemical cross-linking resulted in a homogeneous and non-leaking ionogels. X-TEHIG was characterized by electrochemical impedance spectroscopy, cyclic voltammetry, scanning electron microscopy, FTIR spectroscopy, Seebeck coefficient, and thermal conductivity. Thermoelectric figure of merit of X-TEHIG was calculated at room temperature using Equation (1). LIR 2032 stainless steel coin cells were fabricated to measure ionic conductivity, Seebeck coefficient and cyclic voltammograms of X-TEHIG. Thus, the applications of X-TEHIG in thermoelectric energy conversion can bring several advantages like reduced fabrication cost while maintaining the high value of ionic conductivity and Seebeck coefficient. 


\section{Experimental Procedures}

\subsection{Materials}

All the chemicals and solvents mentioned in this study were used as received unless otherwise stated. Triethyl amine (99\%), 1 bromooctane (99\%), diethyl ether (99\%), and ethanol were purchased from Sigma Aldrich. Polyethylene glycol 200 dimethacrylate was purchased from Geo Specialty Chemicals, USA.

\subsection{Preparation of $\mathrm{N}, \mathrm{N}, \mathrm{N}$ triethyl octyl ammonium bromide $\left[\mathrm{N}_{2228}\right] \mathrm{Br}$ :}

The N, N, N, triethyl octyl ammonium bromide [N2228] Br is synthesized according to the methodology elaborated in the literature [20,21]. Briefly, the equimolar ratio of triethyl amine and 1-bromooctane was refluxed at $353 \mathrm{~K}$ in the ethanolic solution for $24 \mathrm{hrs}$. After the reaction, the solvent was evaporated. The white precipitates of $\left[\mathrm{N}_{2228}\right] \mathrm{Br}$ obtained were washed for five times with petroleum ether to remove unreacted alkyl bromide. The final product was dried under a vacuum of $760 \mathrm{mmHg}$ at $348 \mathrm{~K}$ for 48 hours. Figure 1 displays the schematic diagram for the synthesis of IL.

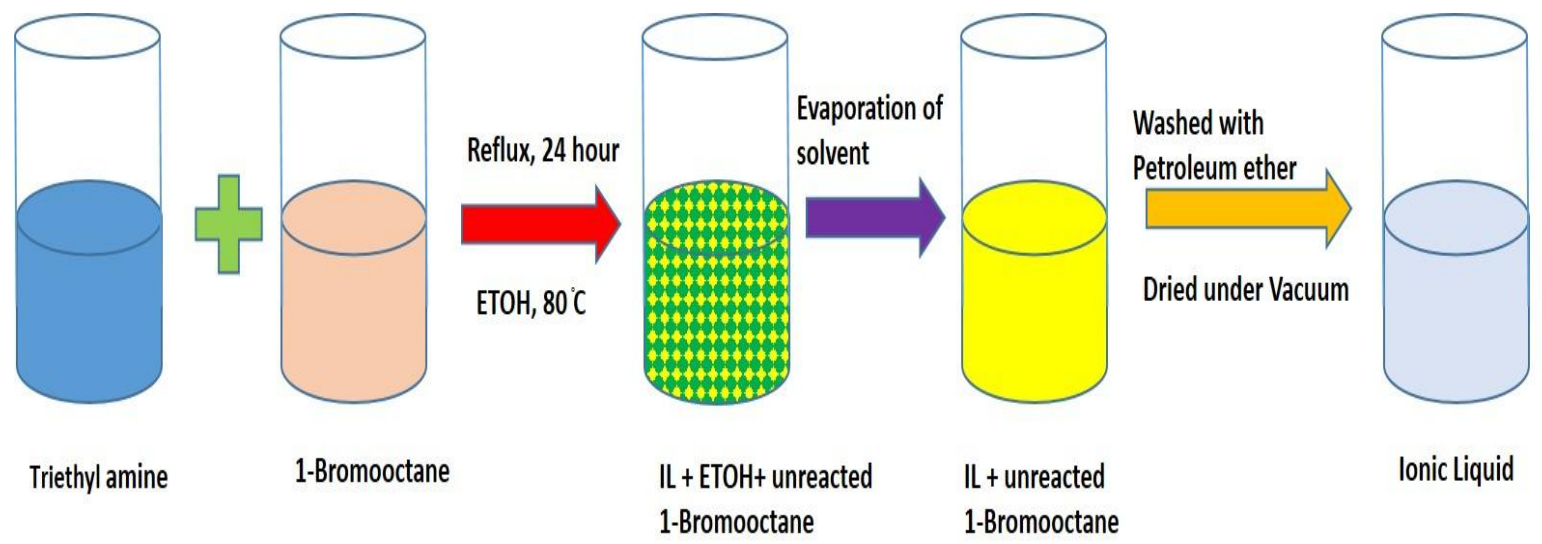

Figure 1. The schematic diagram for the synthesis of ionic liquid

\subsection{Preparation of $\mathrm{X}$-TEHIG}

As discussed in the literature, ionogels are prepared by trapping an ionic liquid in the polymer architecture. In order to initiate the gelation process, an initiator is also desired. The successful synthesis of the X-TEHIG depends upon the solubility of the ionic liquid, base polymer, and the initiator. If either of the constituents is insoluble with each other, the gelation process may not be performed properly [36]. In the current set of experiments, [N2228] Br was used as the IL, PEGDMA as the polymer matrix and AIBN as the radical initiator. The $\left[\mathrm{N}_{2228}\right] \mathrm{Br}$ was compatible with bifunctional monomers of PEGDMA which means that no phase separation between the ionic liquid and the monomer occurred and the solution was clear and transparent [26]. X-TEHIG was prepared by mixing $2 \mathrm{~g}$ of $\left[\mathrm{N}_{2228}\right] \mathrm{Br}$ with $0.5 \mathrm{~g}$ of PEGDMA loaded with $1 \mathrm{wt}$. \% AIBN as radical initiator. In order to enhance the ionic conductivity, $2 \mathrm{ml}$ of deionized water was added as shown in Figure S1. Later the precursor was subjected to $90^{\circ} \mathrm{C}$ for 15 minutes for the thermally initiated free radical polymerization. All the steps involved in the synthesis of $\mathrm{X}$-TEHIG have been shown in Figure S2. 


\subsection{Characterization}

141 The whole assembly of LIR 2032 stainless steel coin cell with its different parts represented by $\mathrm{C}_{1}, \mathrm{C}_{2}$, $142 \mathrm{C}_{3} \ldots \mathrm{C}_{7}$ is shown in Figure S3. The measurement of Seebeck coefficient, ionic conductivity, power output and cyclic voltammetry of X-TEHIG were performed using the fabrication of coin cell. A graphene electrode was placed in the top half of the battery casings (smallest half, denoted by $\mathrm{C}_{7}$ in Figure S3). Then cell was filled with X-TEHIG and another graphene electrode was placed above X-TEHIG followed by spacer and washer. The bottom of the battery casings was then placed over the top and sealed. The measurement of ionic conductivity of pure Ionic liquid was carried out by using DZS-708 multiparameter analyzer (Cheetah Inc.). The ionic conductivity measurement range of DZS-708 multiparameter analyzer is from $0.000 \mu \mathrm{S} / \mathrm{cm} \sim 199.9 \mathrm{mScm}^{-1}$ with an accuracy of $\pm 0.5 \% \mathrm{FS}$.

The ionic conductivity of X-TEHIG was measured in a coin cell by means of alternating current (AC) impedance spectroscopy using Gamry reference 600 instrument in the frequency range $1 \mathrm{~Hz}$ and 100000 $\mathrm{Hz}$ with an amplitude of $10 \mathrm{mV}$. The Gamry reference 600 can generate sine waves with frequency ranging from $1 \mathrm{~m} \mathrm{~Hz}$ to $1 \mathrm{M} \mathrm{Hz}$. With reference 600 the impedance can be measured with $2 \%$ error at a frequency of $1 \mathrm{M} \mathrm{Hz}$ and it has 11 current ranges from $600 \mathrm{~mA}$ to $60 \mathrm{PA}$. The analysis was carried out in temperature range from $300 \mathrm{~K}$ to $343 \mathrm{~K}$. The sample was allowed to achieve thermal equilibrium at each temperature for 20 minutes before conducting the measurements for the impedance of X-TEHIG. The Seebeck coefficient was investigated by creating the temperature gradient between two electrodes of a coin cell. The temperature of the cold electrode was maintained at $25^{\circ} \mathrm{C}$ while the temperature of the hot electrode was increased from room temperature to $65{ }^{\circ} \mathrm{C}$ and corresponding temperature differences $(\Delta \mathrm{T})$ were noted by connecting the electrodes with thermocouples. The open circuit voltage $\left(\mathrm{V}_{\mathrm{oc}}\right)$ was measured by Agilent $34461 \mathrm{~A}_{1 / 2}$ digital Multi-meter. Agilent $34461 \mathrm{~A}_{1 / 2}$ digital Multi-meter can measure up to $1000 \mathrm{~V}$ with $61 / 2$ digits resolution and basic accuracy of $0.0035 \%+0.0005 \%$. The value of the Seebeck coefficient was calculated from the slope of the graph between $\mathrm{V}_{\text {oc }}$ and $\Delta \mathrm{T}$. instrument from Linseis (Germany) with a power heater of $20 \mathrm{~mW}$ and measuring the current of $5 \mathrm{~mA}$. THB has a thermal conductivity measurement range from 0.01 up to $500 \mathrm{~W} /(\mathrm{m} . \mathrm{K}$ ) with an accuracy better than 5\%. The principle of THB 500 is based on newly developed Quasi-Steady-State (QSS) method for the measurement of thermal conductivity. The Hotpoint sensor with the small size of $4.5 \mathrm{~mm}$ is a development of the QSS sensor and allows measurements of a big variety of applications, with small sample sizes. Due to its small size, side effect can be neglected. The temperature dependence of thermal conductivity was measured using the Memmert WNB22 water bath setup.

In order to investigate the kinetics between the X-TEHIG and the electrodes, the cyclic voltammetry was performed with a potential range of -0.7 to $0.1 \mathrm{~V}$ at a scan rate of $50 \mathrm{mVs}^{-1}$. Chemical structure of samples was observed by Fourier transform infrared spectroscopy (FTIR) using Perkin Elmer (FTIR-Spectrometer 400 , United States) with a resolution of $4 \mathrm{~cm}^{-1}$ in the transmission mode with wavenumber ranging from $7800-600 \mathrm{~cm}^{-1}$. Scanning electron microscopy images of the X-TEHIG sample were obtained on Phenom ProX desktop SEM operating at $10 \mathrm{KV}$. X-TEHIG sample freeze dried and coated with gold before SEM 
mapping were carried out to observe the confinement of IL in the polymer matrix. Thermoelectric figure of merit, ZT of X-TEHIG was calculated at room temperature using Equation (1). Figure 2 displays the experimental set up for measurement of Seebeck coefficient. Power was measured by using the formula $\mathrm{P}=\Delta \mathrm{V}^{2} / \mathrm{R}$ mentioned by Hasan et al. [40]. Power and current were converted into power and current densities by dividing them over the exposed surface area inside LIR 2032 casings.

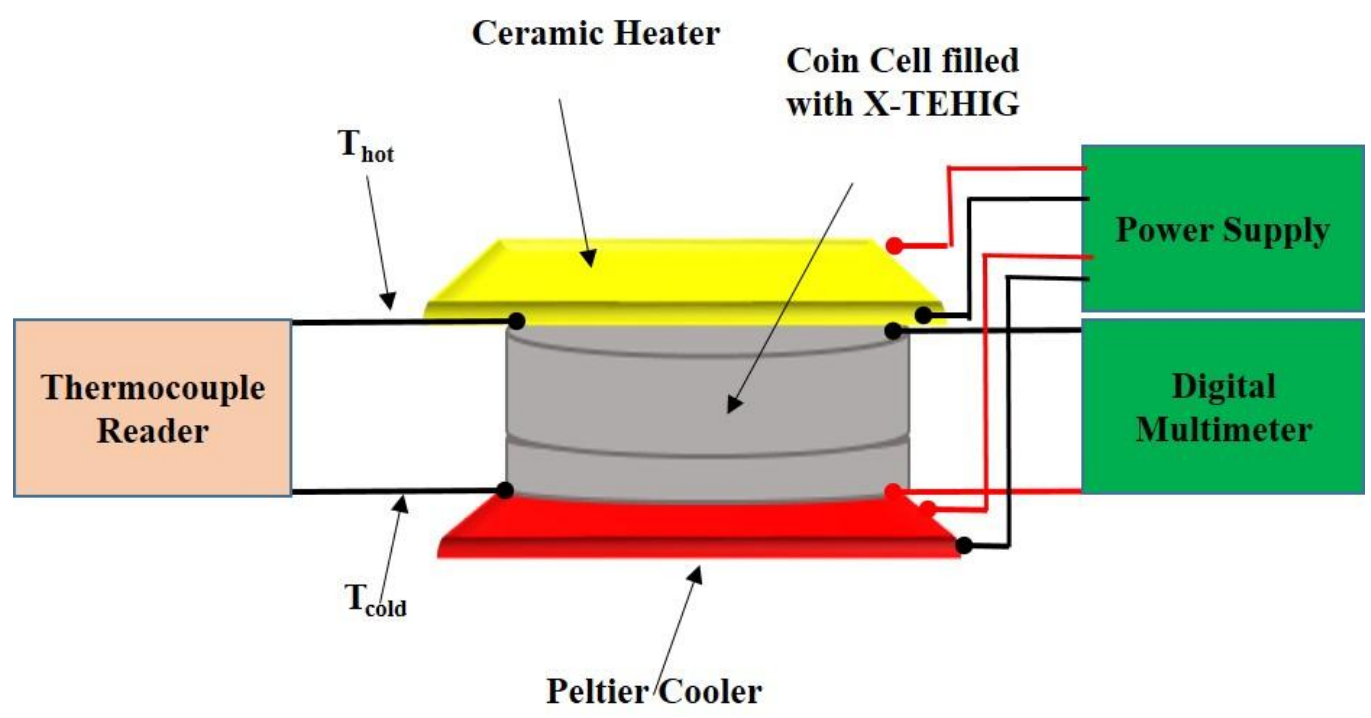

Figure 2. Experimental set up for measurement of Seebeck coefficient.

\section{Results and discussions}

\subsection{Synthesis of X-TEHIG}

The X-TEHIG was prepared by the free radical polymerization of PEGDMA at $90{ }^{\circ} \mathrm{C}$ in the presence of AIBN as an initiator in ionic liquids/water as solvent system. The chemical reaction for the synthesis of $\mathrm{X}$-TEHIG, stepwise polymerization process and hydrogen bonding between water molecules and bromide anions have been shown in Figure 3 (a), (b) and (c) respectively. In the initiation step, the AIBN is decomposed at a temperature above $60{ }^{\circ} \mathrm{C}$ to form free nitrogen molecule and free radicals which attach on the olefinic bond in the PEGDMA resulting in a new free radical on one of the carbon involved in olefinic bond [41]. This free radical on carbon continue to attack the neighboring molecules and chain growth continues. When the concentration of the repeating units decreases to very low value the termination takes place by the combination of the growing ends of the chains. 
(a)

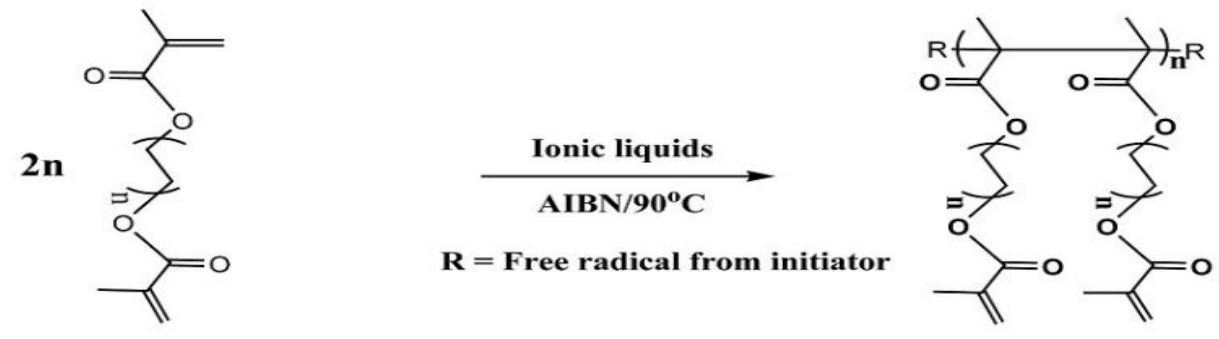

(b)

i) Initiation Step

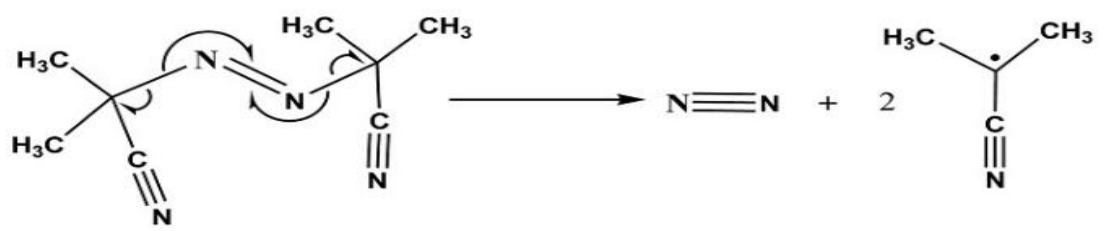

ii) Propagation Step

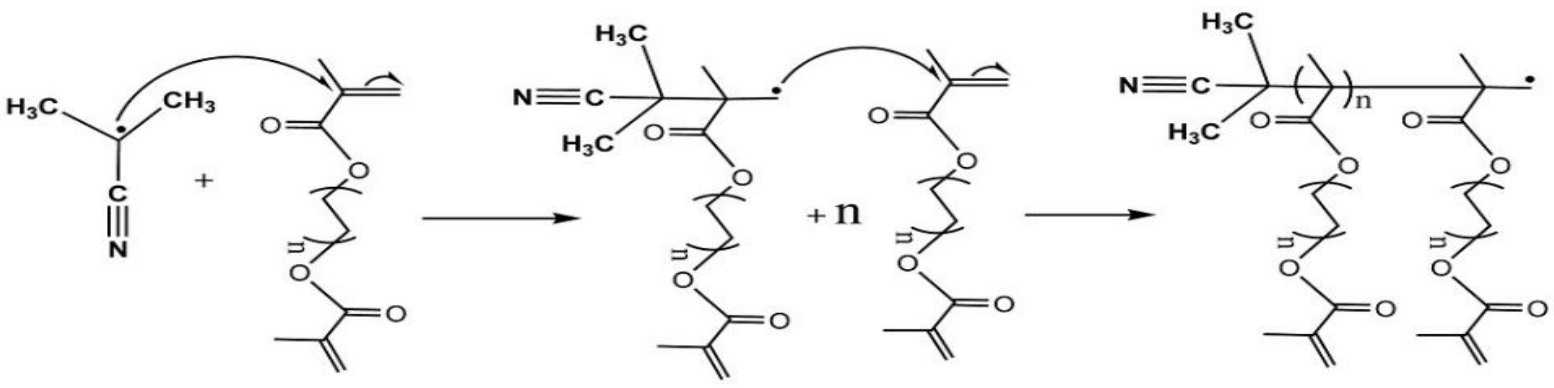

iii) Termination Step

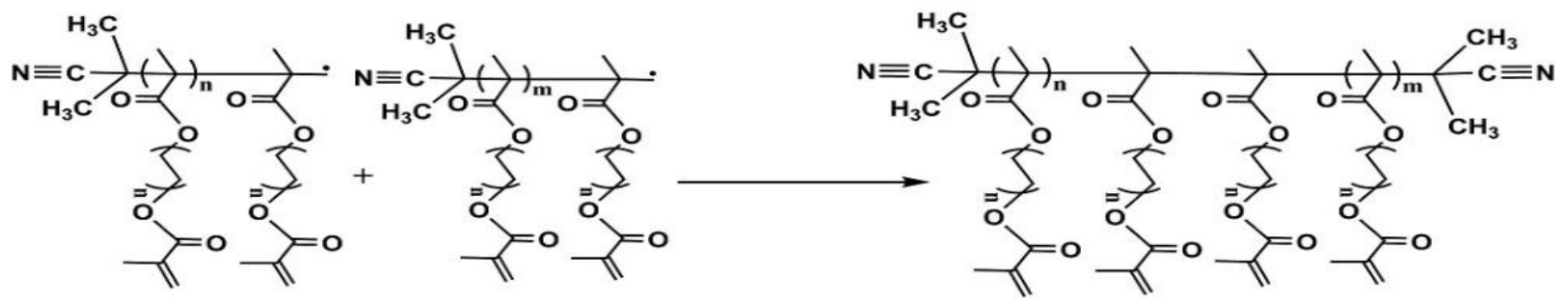




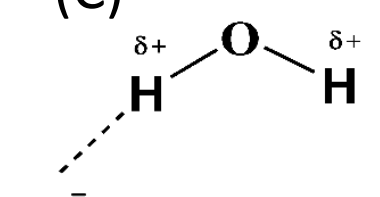

$$
\mathbf{B r}
$$

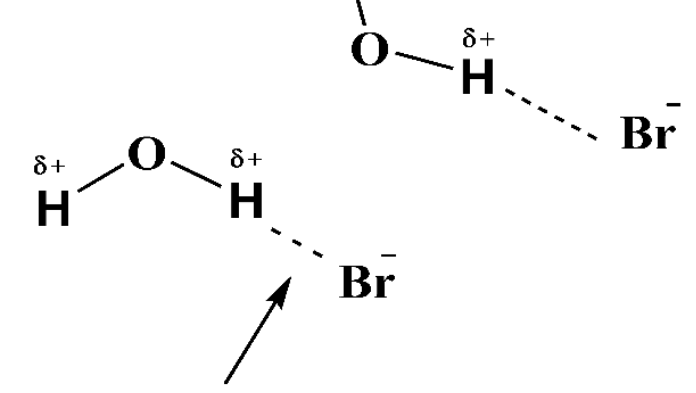

Figure 3. (a) Reaction between PEGDMA and free radicals of AIBN. (b) The proposed reaction mechanism for the formation of X-TEHIG. (C) Hydrogen bonding between water and bromide anion.

\subsection{FTIR Spectroscopy and Microstructure of X-TEHIG}

bonds formed. Figure 4 displays the FTIR spectra of IL, IL + water, PEGDMA, and X-TEHIG. The asymmetric vibrations of $-\mathrm{CH}_{3}$ at $2926 \mathrm{~cm}^{-1}$ and $\mathrm{C}-\mathrm{H}$ symmetric vibrations of $-\mathrm{CH}_{3}$ at $2856 \mathrm{~cm}^{-1}$. All the peaks observed in the IL spectrum are in good agreement with the literature [42]. Upon the addition of water into IL, the peak representing the $\mathrm{N}-\mathrm{H}$ stretch became broader and demonstrated red shift of $52 \mathrm{~cm}^{-1}$ which indicates the strength of hydrogen bonding [43]. It is due to the reason that the addition of water introduced more intramolecular hydrogen bonding due to heteromolecular interaction at the N-H group.

In the FTIR spectrum of PEGDMA, the peak at $2872 \mathrm{~cm}^{-1}$ is for symmetric C-H stretch of the methyl group and the characteristic peak at $1714 \mathrm{~cm}^{-1}$ represents carbonyl group $(\mathrm{C}=\mathrm{O})$ of methyl acrylate group. The olefinic bond $(C=C)$ in methacrylate group showed absorbance peaks at $940 \mathrm{~cm}^{-1}$ and $1637 \mathrm{~cm}^{-1}$ in the spectrum of PEGDMA. Whereas, these peaks have been disappeared in the spectrum of X-TEHIG which confirms the consumption of olefinic $(\mathrm{C}=\mathrm{C})$ bond during the free radical polymerization and successful formation of the X-TEHIG as evident from physical appearance [44, 45]. We can observe that there are no new peaks in X-TEHIG spectrum, demonstrating it is a superposition of the two peaks. The 

detail. To observe the architecture of the matrix more directly and clearly, X-TEHIG sample was freeze-

237 dried and coated with gold before SEM observations. Figure 5 shows the typical SEM images of X-

238 TEHIG. Elemental mapping of X-TEHIG establishes that cations and anions of the IL are evenly 239 distributed in the polymer matrix as shown in Figure S4. This microstructure analysis specifies that IL is 240 continuous and apparently spreads through all of the polymer matrix.

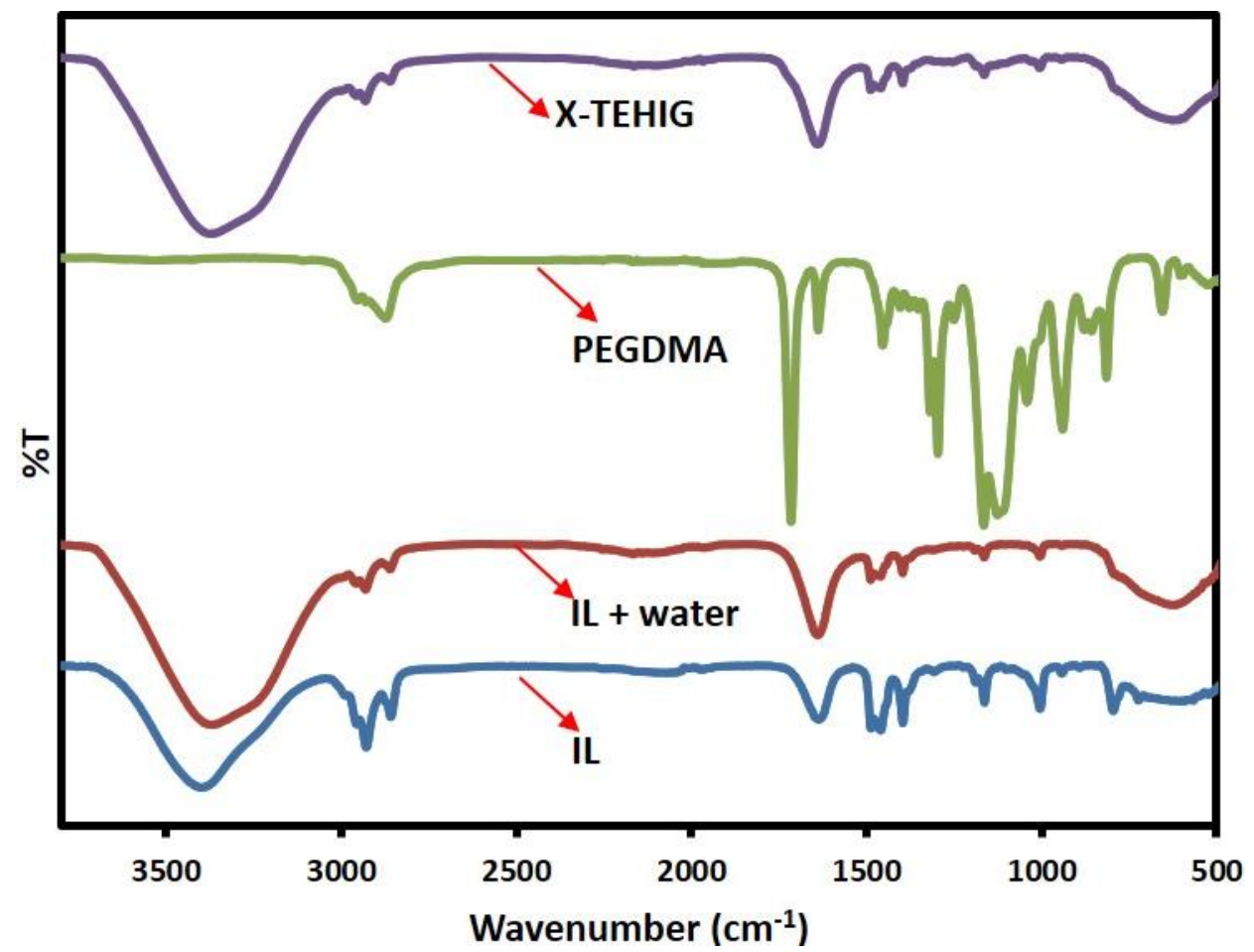

242 Figure 4. FTIR spectrum of IL, IL plus water, PEGDMA, and X-TEHIG. 

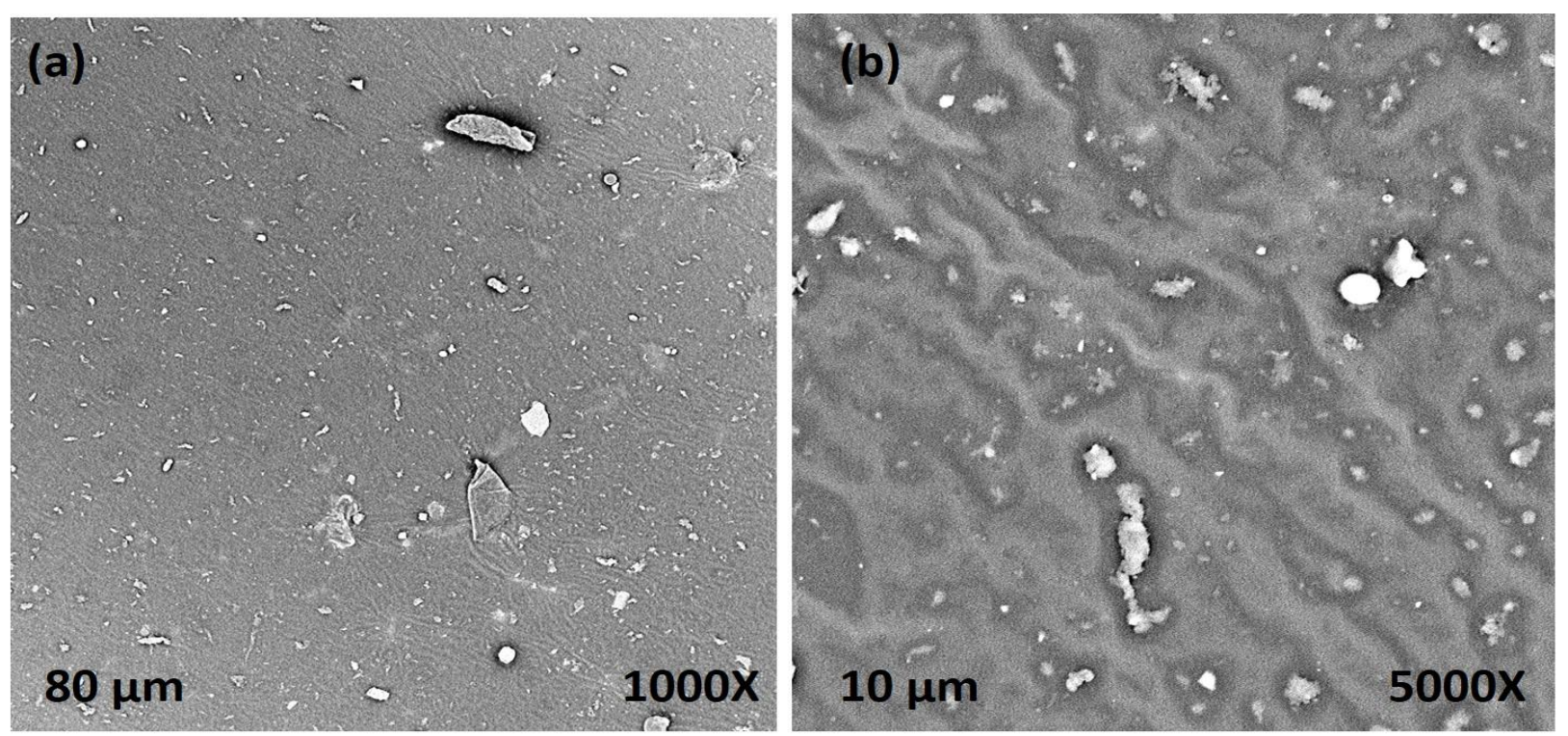

244

245

Figure 5. Typical SEM images of X-TEHIG showing the confinement of IL in Polymer matrix at two different magnifications (a) 1000X (b) 5000X.

\subsection{Ionic conductivity}

The ionic conductivity of pure $\left[\mathrm{N}_{2228}\right] \mathrm{Br}$ was $5.7 \mathrm{mScm}^{-1}$ at room temperature. Although, the intrinsic ionic conductivity of the IL is important, however; the final ionic conductivity of the X-TEHIG is more useful. As discussed in literature the conductivity of ILs increases with the addition of water [20]. Upon the addition of water into neat $\left[\mathrm{N}_{2228}\right] \mathrm{Br}$, it was totally miscible with water. In Figure S1 (Supplementary information) we plot the ionic conductivity of IL versus the percentage in weight of water. From Figure $\mathrm{S} 1$ it was revealed that maximum ionic conductivity of IL plus water was observed at $50 \mathrm{wt} \%$ of the water in IL plus water mixture and then starts decreasing with the further addition of water. The same trend was also reported by Villa et al. [46]. That is why during the synthesis of X-TEHIG we used an equal amount of IL and water. After addition of water, the conductivity of IL increased 5 times as compared with that of neat IL. According to hole model, which is one of the most appropriate models to explain the ionic conductivity of ILs, the addition of water into ILs weakens the intermolecular interactions and as a result, ionic mobility is increased [47]. The general strategy to evaluate the ionic conductivity of the solid electrolytes or porous membranes within the batteries is through Electrochemical Impedance Spectroscopy. As displayed in Figure 6 "Nyquist" plot is used to portray the relation between real $\left(Z^{\prime}\right)$ and imaginary $\left(Z^{\prime \prime}\right)$ parts of impedance. The $x$-axis intercept of the Nyquist plot shows the bulk resistance $\left(R_{b}\right)$ of the X-TEHIG which is generally utilized to evaluate ionic conductivity $(\sigma)$ through the Equation (2).

$$
\sigma=\frac{L}{A \cdot R_{b}}
$$

where $L(\mathrm{~cm}), A\left(\mathrm{~cm}^{2}\right)$ and $R_{b}(\Omega)$ are the thickness of the gel, area of the electrodes and bulk resistance of the X-TEHIG respectively [33]. The ionic conductivity of X-TEHIG at room temperature was 45.3 $\mathrm{mScm}^{-1}$.It is noteworthy that the conductivity of the X-TEHIG is 8 times higher than that of neat IL $\left[\mathrm{N}_{2228}\right] \mathrm{Br}$, showing that the ionic movement has been improved. Previous reports demonstrated that the 
conductivity of ionogels is at best equal to or slightly higher than that of neat IL. Aleksandra and coworkers have also reported slightly higher ionic conductivity of supramolecular ionogel than that of neat ionic liquid 1-butyl 3-methyl imidazolium tetrafluoroborate [48]. High ionic conductivity of PEDOT: PSS/IL films as compared with that of pure PEDOT: PSS and IL have been published by Liu et al. Origin of this higher value of conductivity was attributed to interactions between poly ionic PEDOT; PSS and IL. There is a linear increase in the ionic conductivity of the X-TEHIG with an increase in temperature as shown in Figure 7 and the highest conductivity of $74 \mathrm{mScm}^{-1}$ at $70^{\circ} \mathrm{C}$ was achieved. This increase is attributed to an increase in mobility of ions resulting from a decrease in viscosity with an increase in temperature [49]. In ionic liquids, cation and anion form ion clusters or aggregates because each cation is surrounded by anions and vice versa. Consequently, all of the diffusive species do not contribute to the ionic conductivity because some associated species are neutral and carry no electric charge. The question arises what are the reasons for the pronounced increase in ionic conductivity of $\left[\mathrm{N}_{2228}\right] \mathrm{Br}$ when confined in the polymer matrix. Due to the interaction of PEGDMA with $\left[\mathrm{N}_{2228}\right]^{+}$and $\mathrm{Br}^{-}$the electrostatic force of attraction between $\left[\mathrm{N}_{2228}\right]^{+}$and $\mathrm{Br}^{-}$decreases. Hence, the trend to form ion clusters or aggregates decreases which in turn increases the number of ion carriers and ionic conductivity of the X-TEHIG [46, 48]. Timmer et al. reported that in aqueous solutions containing halide anions, new types of hydrogen bonds are formed between water and anions like $\mathrm{O}-\mathrm{H} \cdots \mathrm{X}^{-}$( where $\mathrm{X}^{-}=\mathrm{F}^{-}, \mathrm{Cl}^{-}, \mathrm{Br}^{-}$) [50]. In our work new hydrogen bonds between water and bromide anion $(\mathrm{O}-\mathrm{H} \cdot \cdots \mathrm{Br})$ are formed as shown in Figure 3 (c). So, another reason for the enhancement of ionic conductivity of X-TEHIG is the high dielectric constant of water and its ability to form hydrogen bonds with the anion of the IL which effectively breaks the ion aggregates [51]. The increase in ionic conductivity of X-TEHIG is also supported by its cyclic voltammetry curve indicating 20 times higher conduction of current as compared with that of neat $\left[\mathrm{N}_{2228}\right]$ $\mathrm{Br}$. The high ionic conductivity of ionogels ensured their use in thermoelectric modules for low-grade heat harvesting.

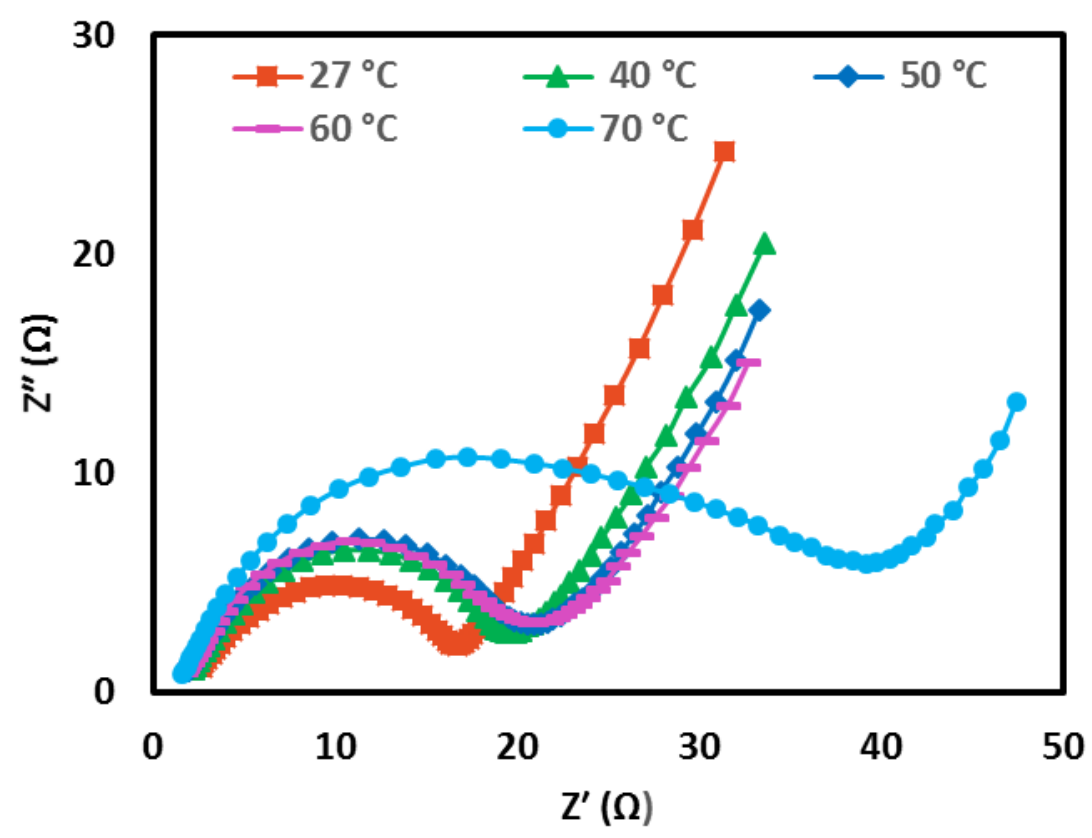


Figure 6. Impedance spectra of X-TEHIG at 27, 40, 5060 , and $70{ }^{\circ} \mathrm{C}$. It shows that with an increase in temperature the resistance of X-TEHIG decreases. At high frequencies, the real part of complex impedance ( $\left.Z^{\prime}\right)$ shows resistive behavior of X-TEHIG [52].

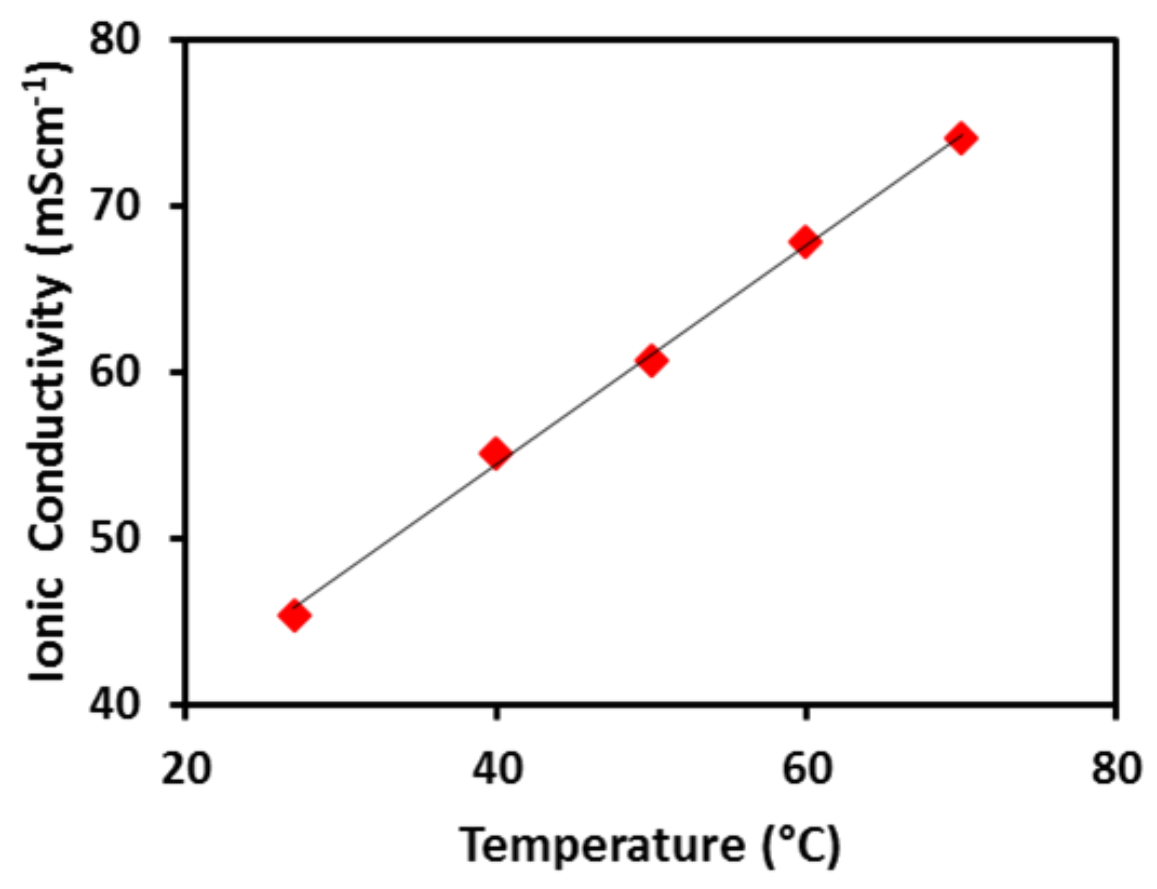

298 Figure 7. Temperature dependence of ionic conductivity of X-TEHIG.

\subsection{Seebeck Coefficient}

According to Equation (1), ZT is directly related to the square of Seebeck coefficient which is another important parameter for thermoelectric materials. The Seebeck coefficient and electrical conductivity of thermoelectric polymers are also interdependent analogous to inorganic semiconductors. With the increase in mobility of the charge carriers, both Seebeck coefficient and electrical conductivity can be increased simultaneously [53]. Figure 8 represents the plot of measured potential differences versus temperature differences. The value of the Seebeck coefficient of the IL $\left[\mathrm{N}_{2228}\right] \mathrm{Br}$ is $0.12 \mathrm{mVK}^{-1}$. The Seebeck coefficient of an IL is closely related to the structural entropy induced by temperature gradient. The Seebeck coefficient of X-TEHIG is $1.38 \mathrm{mVK}^{-1}$ which is 11 times higher than that of pure IL.

The Seebeck coefficient is due to the thermodiffusion of cations and anions in the ionic liquid and XTEHIG. The enhanced value of the Seebeck coefficient of X-TEHIG than that of pure IL implies that cations diffuse more easily in X-TEHIG as compared with pure IL. This can be linked with dissociation of ion aggregates as a result of interaction between IL and polymer matrix as comprehensively discussed in ionic conductivity section. The hydrogen bonds between water and bromide anion $\left(\mathrm{O}-\mathrm{H} \cdot \cdots \mathrm{Br}^{-}\right)$makes the $\mathrm{Br}^{-}$anion less mobile than that of cations. Another reason for the higher Seebeck coefficient of XTEHIG lies in our use of optimal wt. \% of the water in IL. As a consequence of the addition of water into $\mathrm{IL}$, the maximum ionic conductivity of water plus IL mixture was achieved at $50 \mathrm{wt} \%$ of the water in IL and with further increase in the concentration of water it starts decreasing. There are two different mechanisms in electrical conduction. The increase in a number of ions increases the conductivity of the 
ions but at the same, it decreases the mobility of ions which reduces the Seebeck coefficient. But at 50 wt. $\%$ of the water in IL, both effects are optimal and this phenomenon is responsible for the high value of ionic conductivity and Seebeck coefficient of X-TEHIG. The increment in the Seebeck coefficient is very important indicator for the thermoelectric performance of the X-TEHIG. The basic theoretical definition of the Seebeck coefficient can be expressed as $S=\Delta V / \Delta T$, which implicates the capability of the materials to transform the applied thermal gradient into the potential gradient. Our X-TEHIG can convert the thermal gradient into the potential gradient $91 \%$ more efficiently as compared to the IL $\left[\mathrm{N}_{2228}\right] \mathrm{Br}$. According to linear regression analysis, standard errors in measurement of Seebeck coefficient of IL and $\mathrm{X}$-TEHIG are $0.45 \%$ and $1.12 \%$ respectively. In regression statics the p-value, less than 0.05 shows statically significant data. The respective p-values for of IL and X-TEHIG were found to be 0.006 and 0.0001. The synthesized novel crosslinked thermoelectric hydroionogels (X-TEHIG) which demonstrated high Seebeck coefficient and reduced fabrication cast holds promise for the efficient harvest of low-grade thermal energy.

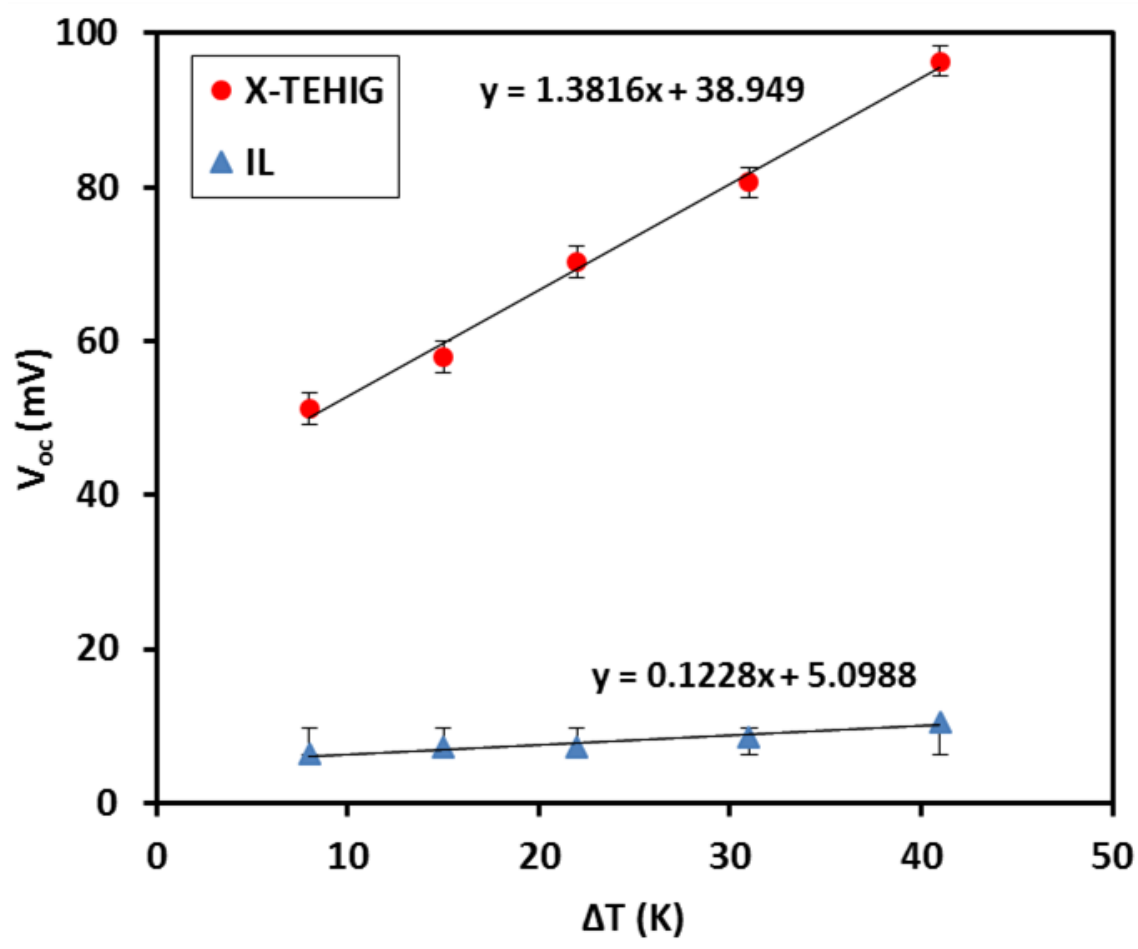

Figure 8. A comparison of the Seebeck coefficient of IL and X-TEHIG.

\subsection{Thermal Conductivity}

The thermal conductivities of IL and X-TEHIG at various temperatures are shown in Figure 9. The thermal conductivity of IL at $37^{\circ} \mathrm{C}$ was found to be $0.204 \mathrm{~W} /(\mathrm{m} . \mathrm{K})$ and it showed a small dependence on temperature.

The first-ever report on thermal conductivity of IL was published by Valkenburg et al [54]. Until now, the reported thermal conductivity values of ILs are fewer than other thermophysical properties of ionic liquids. That is why we found no reference for thermal conductivity of our IL, N, N, N triethyl octyl 
ammonium bromide in literature. Thermal conductivity of polymers is very less than inorganic materials and they proved to be ideal for thermoelectric applications [53]. The X-TEHIG demonstrated a thermal conductivity of $0.251 \mathrm{~W} /(\mathrm{m} . \mathrm{K})$ at $37{ }^{\circ} \mathrm{C}$. The higher value of thermal conductivity X-TEHIG as compared with the pure IL can be attributed to the increase in thermal conduction path ways as a result of crosslinking of polymer chains. The presence of cross linker also affects the value of thermal conductivity. Tang et al. also reported an increase in thermal conductivity of hydrogels owing to increase in crosslink bonding between polymer chains. [55]. The error bars in Figure 9 represent the maximum standard deviation of 0.013 and $0.006 \mathrm{~W} /(\mathrm{m} . \mathrm{K})$ for IL and X-TEHIG respectively. The thermal conductivity of X-TEHIG $(0.251 \mathrm{~W} /(\mathrm{m} . \mathrm{K})$ is very much less than the thermal conductivity of agar-agar gel $(0.554 \mathrm{~W} /(\mathrm{m} . \mathrm{K})$ reported by $\mathrm{Wu}$ et al. The reason for this is the lower thermal conductivity of constituents of X-TEHIG i.e. IL $(0.2 \mathrm{~W} /(\mathrm{m} . \mathrm{K})$ and PEG $(0.20-.30 \mathrm{~W} /(\mathrm{m} . \mathrm{K}))$ which has been reported by Sun et al [56]. The thermal conductivity of X-TEHIG demonstrated a relatively weak temperature dependence. A convincing experimental investigation of thermal conductivity of ionogels has not been explored yet. According to Equation (1) in order to achieve the high-performance thermoelectric materials, the thermal conductivity must be low so that the temperature gradient can be maintained for a longer duration. The lower value of thermal conductivity of X-TEHIG guarantees their usage in harvesting the waste heat directly into electricity.

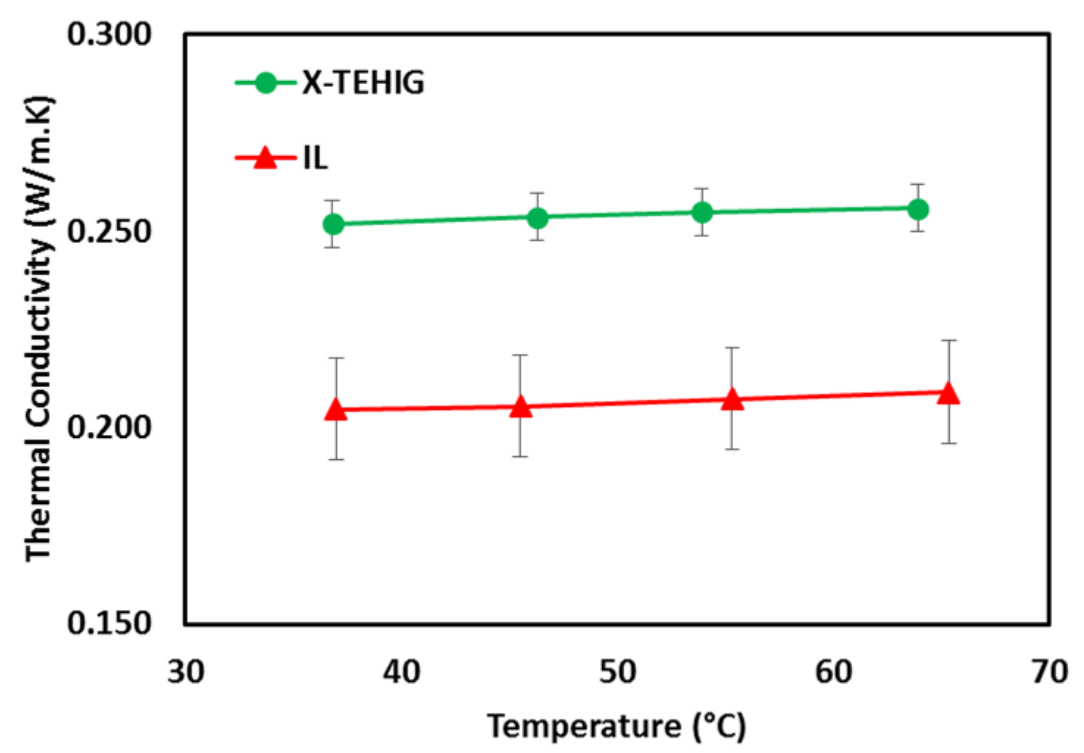

Figure 9. Thermal conductivity of ionic liquid (IL) and X-TEHIG. The error bars represent the standard deviation in the measured data.

\subsection{Cyclic Voltammetry}

ILs containing halides such as bromides, chlorides, and iodides have narrower electrochemical windows because they are easily oxidized [49]. Due to this reason, we observed a narrow electrochemical window of neat $\left[\mathrm{N}_{2228}\right]$ Br. Figure 10 shows the comparison of cyclic voltammograms of IL and X-TEHIG. Cathodic and anodic stability of IL can be determined by reduction and oxidation potential of IL respectively. The positively charged nitrogen ion is undergoing reduction and bromide anion is 
experiencing oxidation represented by the peaks at $420 \mathrm{mV}$ and $310 \mathrm{mV}$ respectively. Cyclic voltammetry of X-TEHIG revealed a large increase in current as compared to that of $\left[\mathrm{N}_{2228}\right] \mathrm{Br}$ which shows the highly conductive nature of X-TEHIG. In case of X-TEHIG maximum current is $200 \mu \mathrm{A}$ which is 20 times high peak current of pure $\left[\mathrm{N}_{2228}\right] \mathrm{Br}$. Increase in the magnitude of the current is in agreement with the observation of Susan et al. who proved that more number of charge carriers are present in 373 ionogel as compared to pure IL [46].

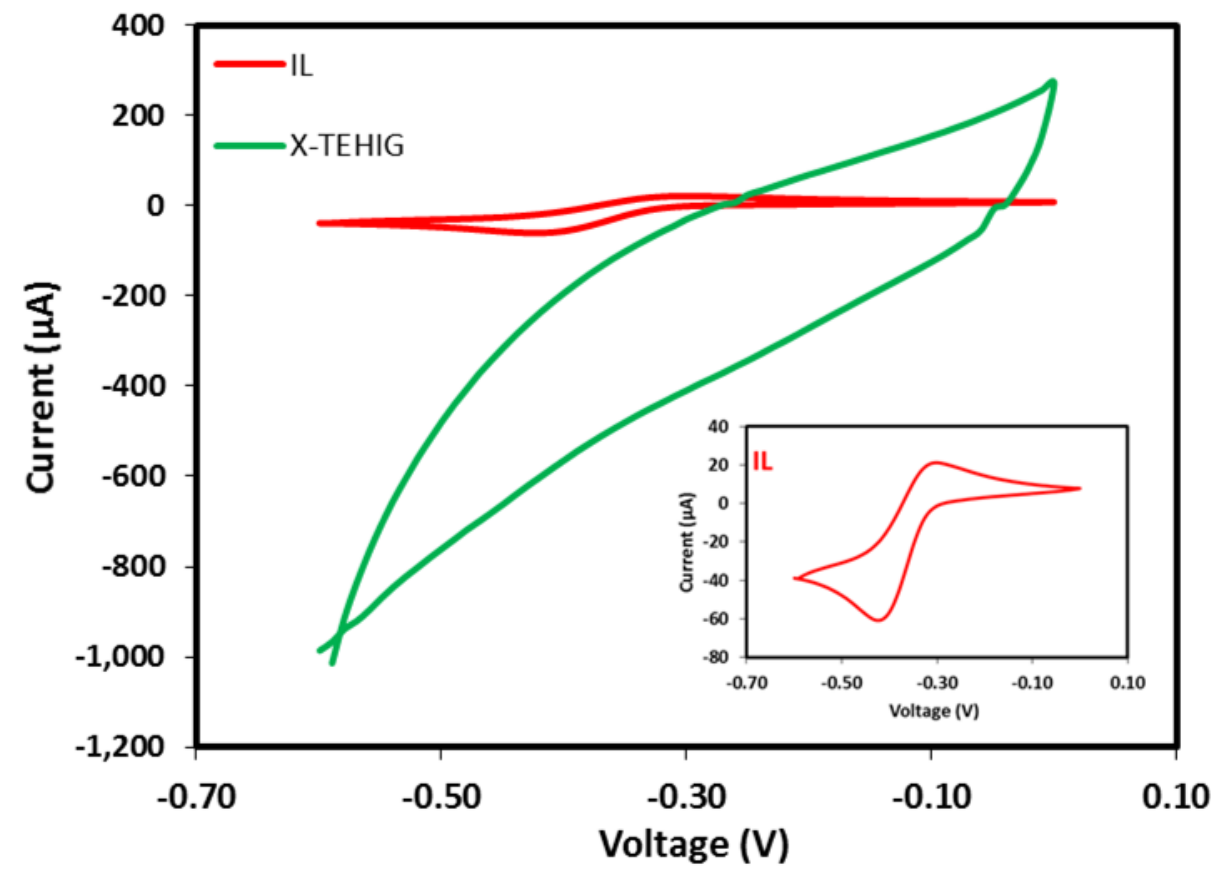

Figure 10. Comparison of cyclic voltammograms of IL and X-TEHIG. Inset shows the CV of IL.

\subsection{Power and current output}

The power and current output densities of X-TEHIG were calculated by measuring the potential difference values and known resistance values using the formula, $P=V^{2} / R$ and $I=V / R$ respectively and divided by electrode area. The output power density showed the parabolic relationship as displayed in Figure 11 and the maximum value of power density achieved was (measured at $\Delta \mathrm{T}=41{ }^{\circ} \mathrm{C}$ ) $232 \mathrm{n} \mathrm{W} / \mathrm{m}^{2}$. Yang et al. prepared the gel electrolyte from Poly vinyl alcohol (PVA) with the addition of two types of redox couples, ferric/ferrous chloride and potassium Ferricyanide/Ferro cyanide with a maximum power output of $18 \mathrm{n} \mathrm{W} / \mathrm{m}^{2}$ [57]. The lower output power as compared with our measured value may be attributed to lack of ionic liquid in their gel electrolyte. Hasan et al. reported the maximum power output of $245 \mathrm{n} \mathrm{W} / \mathrm{m}^{2}$ in membrane-inserted thermoelectrochemical cells (MTECs) with Seebeck coefficient of $0.4 \mathrm{mV} / \mathrm{K}$ but still, leakage problem exists due to the liquid state of electrolytes [58]. Our measured value of Power output is close to their value with higher Seebeck coefficient of $1.38 \mathrm{mV} / \mathrm{K}$ and no leakage issue because of the solid state of X-TEHIG. The X-TEHIG followed Ohm's law and behaves as a simple system, $V=I R$ which implies $V$ is proportional to I and resistance is basically due to charge transport and Ohmic resistances [59]. 
404

The X-TEHIG having significantly higher Seebeck coefficient, ionic conductivity and lower thermal conductivity is suitable as high-performance thermoelectric materials despite a lower power output. Our discovery of X-TEHIG can be utilized in all areas of low-grade heat energy harvesting including solar thermal devices, textile electronics (harvesting body heat), microelectronic processors, and biomedical equipment. Lekbir et al. has reported that most of the incident solar energy on the PV panel is wasted in the form of heat which reduces the efficiency of the PV system [60]. In order to utilize a certain amount of this heat, a thermoelectric generated can be added to the PV system. Owing to high thermoelectric performance, X-TEHIG can be used as TEG in solar PV systems. Although, solid-state thermoelectric materials (e.g. $\mathrm{Bi}_{2} \mathrm{Te}_{3}$ and $\mathrm{Sb}_{2} \mathrm{Te}_{3}$ ) can also be implemented in these areas, however, our novel ionogel has the advantage of being eco-friendly and economic while simultaneously providing higher Seebeck coefficient as compared to the aforementioned materials. We can also predict the application of this high Seebeck coefficient in combination with other polymer electrolyte based devices like electrochromic displays, electrochromic membrane bipolar diodes and bipolar junction transistors [61].

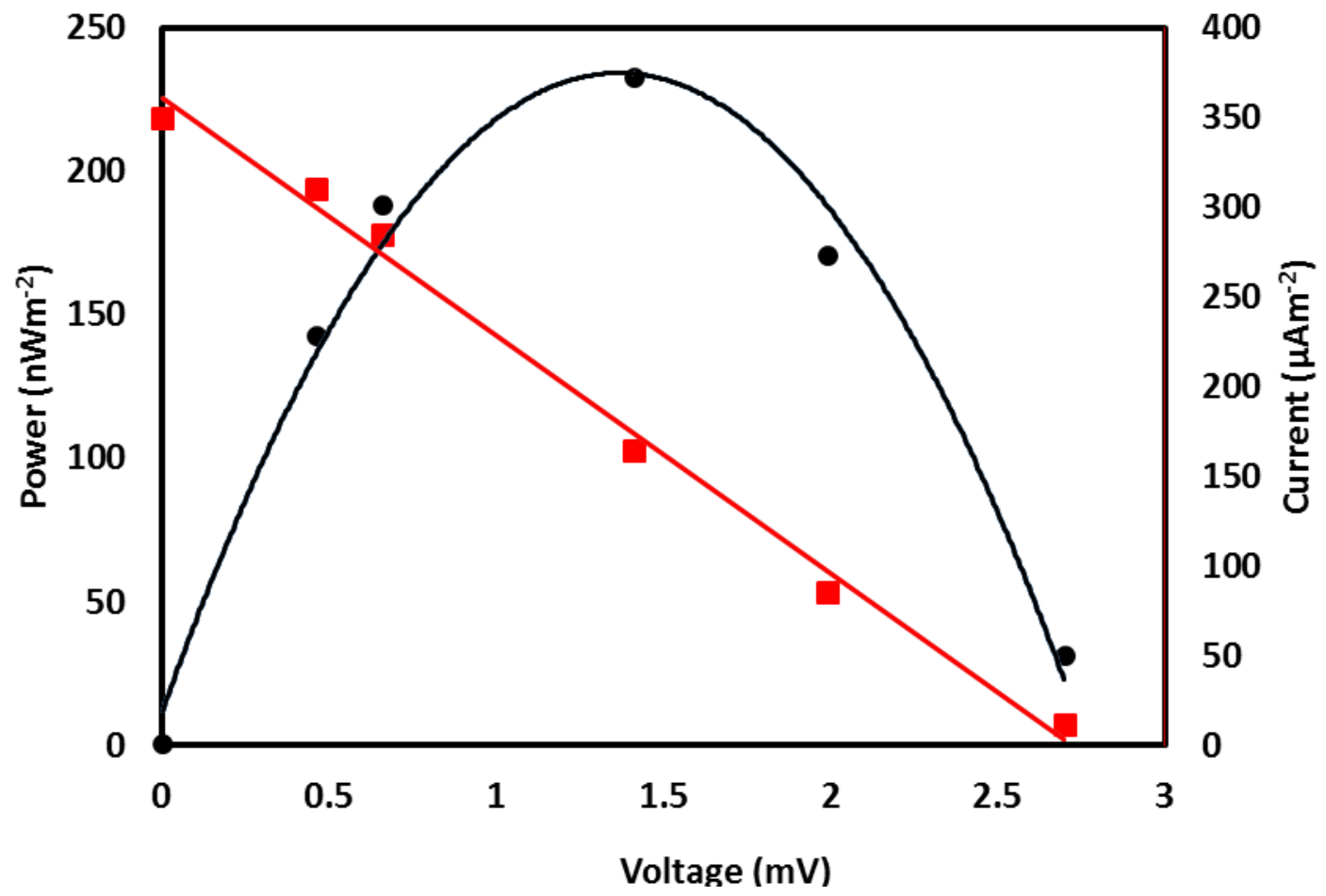

Figure 11. Power and current output density plots of X-TEHIG. The black dot $(\bullet)$ represents power density and red spares ( ) represent current density.

\section{Conclusions}

In conclusion, a novel cross-linked thermoelectric hydro-ionogel (X-TEHIG) has been successfully synthesized by in situ thermally induced free radical polymerization of bifunctional monomers of PEGDMA in presence of IL, N, N, N, triethyl octyl ammonium bromide, water, and AIBN as free radical initiator. The X-TEHIG was investigated by measuring its ionic conductivity, Seebeck coefficient, thermal conductivity, and power output. The most intriguing property of X-TEHIG is their exceptionally high ionic conductivity $\left(74 \mathrm{mScm}^{-1}\right)$, even much higher than that of neat IL. Because of the high dielectric 
constant of water and formation of hydrogen bonds between water and $\mathrm{Br}^{-}$ion aggregates break, consequently increasing the number of ions and conductivity. Similarly, the value of the Seebeck coefficient of $1.38 \mathrm{mVK}^{-1}$ is much higher than that of IL $\left(0.12 \mathrm{mVK}^{-1}\right)$. The value of ZT of X-TEHIG at room temperature was found to be $1.02 \times 10^{-2}$.The conversion of $\mathrm{C}=\mathrm{C}$ bond in methacrylate group of PEGDMA by thermally initiated radical polymerization was confirmed from FTIR analysis of X-TEHIG. Therefore, the above results strongly envisage that this crosslinked thermoelectric hydro-ionogel (XTEHIG) will be a very promising candidate for future thermoelectric applications.

\section{Acknowledgment}

The authors would like to sincerely acknowledge the University of Malaya for the financial support through a postgraduate research grant, PPP grant (Grant No.-PG041-2015B), FRGS (Grant No.FP064/2016) and FRG (Grant No.FG009/17AFR). "R. Saidur would like to acknowledge the financial support provided by the Sunway University through the project no\# STR-RCTR-RCNMET-001-2019". The authors also gratefully acknowledge Prof. Dr. Mohd Ali Bin Hashim from the Chemical Engineering department of the University of Malaya for facilitating the ionic conductivity measurements. 


\section{Refrences:}

454 [1] F. Jiao, A. Naderi, D. Zhao, J. Schlueter, M. Shahi, J. Sundström, et al. Ionic thermoelectric paper. Journal of Materials Chemistry A. 5 (2017) 16883-8.

[2] H. Wang, D. Zhao, Z.U. Khan, S. Puzinas, M.P. Jonsson, M. Berggren, et al. Ionic Thermoelectric Figure of Merit for charging of supercapacitors. Advanced Electronic Materials. 3 (2017) 1700013.

[3] Q. Zhang, Y. Sun, W. Xu, D. Zhu. Organic thermoelectric materials: emerging green energy materials converting heat to electricity directly and efficiently. Advanced Materials. 26 (2014) 6829-51. thermoelectric performance of rough silicon nanowires. Nature. 451 (2008) 163-7.

[5] A. Marvão, P.J. Coelho, H.C. Rodrigues. Optimization of a thermoelectric generator for heavy-duty vehicles. Energy Conversion and Management. 179 (2019) 178-91.

[6] G.J. Snyder, E.S. Toberer. Complex thermoelectric materials. Nature materials. 7 (2008) 105-14.

[7] Y. Chen, Y. Zhao, Z. Liang. Solution processed organic thermoelectrics: towards flexible thermoelectric modules. Energy \& Environmental Science. 8 (2015) 401-22.

[8] S.W. Hasan, S.M. Said, M.F.M. Sabri, A.S.A. Bakar, N.A. Hashim, M.M.I.M. Hasnan, et al. High Thermal Gradient in Thermo-electrochemical Cells by Insertion of a Poly (Vinylidene Fluoride) Membrane. Scientific reports. 6 (2016). 015004.

[10] C. Gayner, K.K. Kar. Recent advances in thermoelectric materials. Progress in Materials Science. 83 (2016) 330-82.

[11] A. Fabián-Mijangos, G. Min, J. Alvarez-Quintana. Enhanced performance thermoelectric module having asymmetrical legs. Energy Conversion and Management. 148 (2017) 1372-81.

[12] O. Caballero-Calero, D.-A. Borca-Tasciuc, R. Martínez-Moro, A. Gorog, M. Mohner, T. Borca-Tasciuc, et al. Improvement of Seebeck coefficient in as-grown Bi2Te3-ySey electrodeposited films by the addition of additives and bath optimization. Electrochimica Acta. 269 (2018) 490-8.

[13] A. Danine, J. Schoenleber, J. Ghanbaja, F. Montaigne, C. Boulanger, N. Stein. Microstructure and thermoelectric properties of $p$-type bismuth antimony telluride nanowires synthetized by template electrodeposition in polycarbonate membranes. Electrochimica Acta. 279 (2018) 258-68.

[14] B. Zhang, J. Sun, H. Katz, F. Fang, R. Opila. Promising thermoelectric properties of commercial PEDOT: PSS materials and their Bi2Te3 powder composites. ACS applied materials \& interfaces. 2 (2010) 3170-8.

[15] T.A. Siddique, S. Balamurugan, S.M. Said, N.A. Sairi, W.M.D.W. Normazlan. Synthesis and characterization of protic ionic liquids as thermoelectrochemical materials. Rsc Advances. 6 (2016) 
[16] N. Dubey, M. Leclerc. Conducting polymers: efficient thermoelectric materials. Journal of Polymer Science Part B: Polymer Physics. 49 (2011) 467-75.

[17] M.A. Kamarudin, S.R. Sahamir, R.S. Datta, B.D. Long, M. Sabri, M. Faizul, et al. A review on the fabrication of polymer-based thermoelectric materials and fabrication methods. The Scientific World Journal. 2013 (2013). energy harvesting and temperature control. Nature Reviews Materials. 1 (2016) 16050.

[19] C. Cho, K.L. Wallace, P. Tzeng, J.H. Hsu, C. Yu, J.C. Grunlan. Outstanding Low Temperature Thermoelectric Power Factor from Completely Organic Thin Films Enabled by Multidimensional Conjugated Nanomaterials. Advanced Energy Materials. (2016).

[20] J. Vila, P. Gines, E. Rilo, O. Cabeza, L. Varela. Great increase of the electrical conductivity of ionic liquids in aqueous solutions. Fluid Phase Equilibria. 247 (2006) 32-9.

[21] M.r.m. Anouti, J. Jacquemin, P. Porion. Transport properties investigation of aqueous protic ionic liquid solutions through conductivity, viscosity, and NMR self-diffusion measurements. The Journal of Physical Chemistry B. 116 (2012) 4228-38.

[22] D.R. MacFarlane, N. Tachikawa, M. Forsyth, J.M. Pringle, P.C. Howlett, G.D. Elliott, et al. Energy applications of ionic liquids. Energy \& Environmental Science. 7 (2014) 232-50.

[23] E. Laux, L. Jeandupeux, S. Uhl, H. Keppner, P.P. López, P. Sanglard, et al. Novel lonic Liquids for Thermoelectric Generator Devices. Materials Today: Proceedings. 8 (2019) 672-9.

[24] M. Bielejewski, K. Nowicka, N. Bielejewska, J. Tritt-Goc. Ionic conductivity and thermal properties of a supramolecular ionogel made from a sugar-based low molecular weight gelator and a quaternary ammonium salt electrolyte solution. Journal of the Electrochemical Society. 163 (2016) G187-G95.

[25] A. Guyomard-Lack, J. Abusleme, P. Soudan, B. Lestriez, D. Guyomard, J.L. Bideau. Hybrid silicapolymer ionogel solid electrolyte with tunable properties. Advanced Energy Materials. 4 (2014).

[26] U. Löffelmann, N. Wang, D. Mager, P.J. Smith, J.G. Korvink. Solvent-free inkjet printing process for the fabrication of conductive, transparent, and flexible ionic liquid-polymer gel structures. Journal of Polymer Science Part B: Polymer Physics. 50 (2012) 38-46.

[27] A.F. Visentin, M.J. Panzer. Poly (ethylene glycol) diacrylate-supported ionogels with consistent capacitive behavior and tunable elastic response. ACS applied materials \& interfaces. 4 (2012) 2836-9.

[28] C.-M. Yang, J.B. Ju, J.K. Lee, W.I. Cho, B.W. Cho. Electrochemical performances of electric double layer capacitor with UV-cured gel polymer electrolyte based on poly [(ethylene glycol) diacrylate]-poly (vinylidene fluoride) blend. Electrochimica acta. 50 (2005) 1813-9.

[29] J.T. Delaney, A.R. Liberski, J. Perelaer, U.S. Schubert. A Practical Approach to the Development of Inkjet Printable Functional Ionogels-Bendable, Foldable, Transparent, and Conductive Electrode Materials. Macromolecular rapid communications. 31 (2010) 1970-6.

[30] X. Liu, B. He, Z. Wang, H. Tang, T. Su, Q. Wang. Tough nanocomposite ionogel-based actuator exhibits robust performance. Sci Rep. 4 (2014) 6673.

[31] A. Ghoufi, A. Szymczyk, P. Malfreyt. Ultrafast diffusion of Ionic Liquids Confined in Carbon Nanotubes. Sci Rep. 6 (2016) 28518.

[32] Z. Fan, Y. Wang, Z. Xue, L. Zhang, Y. Chen, S. Zhang. Preparation, characterization and luminescence of transparent thin film of ionogels. Journal of sol-gel science and technology. 72 (2014) 328-33.

[33] C. Liao, X.-G. Sun, S. Dai. Crosslinked gel polymer electrolytes based on polyethylene glycol methacrylate and ionic liquid for lithium ion battery applications. Electrochimica Acta. 87 (2013) 889-94.

[34] M. Brachet, T. Brousse, J. Le Bideau. All solid-state symmetrical activated carbon electrochemical double layer capacitors designed with ionogel electrolyte. ECS Electrochemistry Letters. 3 (2014) A112A5.

[35] A. Vioux, L. Viau, S. Volland, J. Le Bideau. Use of ionic liquids in sol-gel; ionogels and applications. Comptes Rendus Chimie. 13 (2010) 242-55. 
[36] J. Le Bideau, L. Viau, A. Vioux. Ionogels, ionic liquid based hybrid materials. Chemical Society Reviews. 40 (2011) 907-25.

[37] E. Andrzejewska, A. Marcinkowska, A. Zgrzeba. lonogels-materials containing immobilized ionic liquids. Polimery. 62 (2017) 344--52.

[38] S. Farooq, H. Razzaq, S. Razzaque, B.A. Khan, S. Qaisar. Structural and physical impacts of nanofillers in ionogels: A comprehensive overview. Polymer Composites. 40 (2019) E11-E23.

[39] S. Mane, S. Ponrathnam, N. Chavan. Effect of chemical cross-linking on properties of polymer microbeads: A review. Can Chem Trans. 3 (2015) 473-85.

[40] S.W. Hasan, S.M. Said, A.S. Bin Abu Bakar, M.F.M. Sabri, I.H. Sajid, N.A. Hashim. Optimization of poly(vinylidene fluoride) membranes for enhanced power density of thermally driven electrochemical cells. Journal of Materials Science. 52 (2017) 10353-63.

[41] U.S. Ramelow, S. Pingili. Synthesis of ethylene glycol dimethacrylate-methyl methacrylate copolymers, determination of their reactivity ratios, and a study of dopant and temperature effects on their conductivities. Polymers. 2 (2010) 265-85.

[42] H. Li, G. Zhao, F. Liu, S. Zhang. Physicochemical Characterization of MF m--Based Ammonium lonic Liquids. Journal of Chemical \& Engineering Data. 58 (2013) 1505-15.

[43] S. Cha, M. Ao, W. Sung, B. Moon, B. Ahlström, P. Johansson, et al. Structures of ionic liquid-water mixtures investigated by IR and NMR spectroscopy. Physical Chemistry Chemical Physics. 16 (2014) 9591-601.

[44] X. Jiao, D. Zhao, Y. Zhang, Q. Wu, G. Qiu, X. Lu, et al. Synthesis and studies of poly (ethylene glycol dimethacrylate) microcapsule. Colloid and Polymer Science. 294 (2016) 639-46.

[45] S. Bäckström, J. Benavente, R.W. Berg, K. Stibius, M.S. Larsen, H. Bohr, et al. Tailoring properties of biocompatible PEG-DMA hydrogels with UV light. Materials Sciences and Applications. 3 (2012) 425.

[46] M.A.B.H. Susan, T. Kaneko, A. Noda, M. Watanabe. Ion gels prepared by in situ radical polymerization of vinyl monomers in an ionic liquid and their characterization as polymer electrolytes. Journal of the American Chemical Society. 127 (2005) 4976-83.

[47] R. Aranowski, I. Cichowska-Kopczyńska, B. Dębski, P. Jasiński. Conductivity and viscosity changes of imidazolium ionic liquids induced by $\mathrm{H} 2 \mathrm{O}$ and Co2. Journal of Molecular Liquids. 221 (2016) 541-6.

[48] A. Maršavelski, V. Smrečki, R. Vianello, M. Žinić, A. Moguš-Milanković, A. Šantić. Supramolecular Ionic-Liquid Gels with High lonic Conductivity. Chemistry-A European Journal. 21 (2015) 12121-8.

[49] L. Barrosse-Antle, A. Bond, R. Compton, A. O'Mahony, E. Rogers, D. Silvester. Voltammetry in room temperature ionic liquids: comparisons and contrasts with conventional electrochemical solvents. Chemistry-An Asian Journal. 5 (2010) 202-30.

[50] R. Timmer, H. Bakker. Hydrogen bond fluctuations of the hydration shell of the bromide anion. The Journal of Physical Chemistry A. 113 (2009) 6104-10.

[51] W. Li, Z. Zhang, B. Han, S. Hu, Y. Xie, G. Yang. Effect of water and organic solvents on the ionic dissociation of ionic liquids. The Journal of Physical Chemistry B. 111 (2007) 6452-6.

[52] A.I. Horowitz, M.J. Panzer. High-performance, mechanically compliant silica-based ionogels for electrical energy storage applications. Journal of Materials Chemistry. 22 (2012) 16534-9.

[53] B.C. Tee, J. Ouyang. Soft electronically functional polymeric composite materials for a flexible and stretchable digital future. Advanced Materials. (2018) 1802560.

[54] D. Tomida. Thermal Conductivity of Ionic Liquids. Impact of Thermal Conductivity on Energy Technologies. IntechOpen2018.

[55] N. Tang, Z. Peng, R. Guo, M. An, X. Chen, X. Li, et al. Thermal Transport in Soft PAAm Hydrogels. Polymers. 9 (2017) 688.

[56] Q. Sun, Y. Yuan, H. Zhang, X. Cao, L. Sun. Thermal properties of polyethylene glycol/carbon microsphere composite as a novel phase change material. Journal of Thermal Analysis and Calorimetry. 130 (2017) 1741-9. 
[57] P. Yang, K. Liu, Q. Chen, X. Mo, Y. Zhou, S. Li, et al. Wearable thermocells based on gel electrolytes for the utilization of body heat. Angewandte Chemie International Edition. 55 (2016) 12050-3.

587 [58] S.W. Hasan, S.M. Said, M.F.M. Sabri, A.S.A. Bakar, N.A. Hashim, M.M.I.M. Hasnan, et al. High 588 thermal gradient in thermo-electrochemical cells by insertion of a poly (vinylidene fluoride) membrane. 589 Scientific reports. 6 (2016) 29328.

590 [59] H. Im, H.G. Moon, J.S. Lee, I.Y. Chung, T.J. Kang, Y.H. Kim. Flexible thermocells for utilization of body 591 heat. Nano Research. 7 (2014) 443-52.

592 [60] A. Lekbir, S. Hassani, M.R. Ab Ghani, C.K. Gan, S. Mekhilef, R. Saidur. Improved energy conversion 593 performance of a novel design of concentrated photovoltaic system combined with thermoelectric 594 generator with advance cooling system. Energy Conversion and Management. 177 (2018) 19-29.

595 [61] H. Ikeda, F. Khan, P. Veluswamy, S. Sakamoto, M. Navaneethan, M. Shimomura, et al. 596 Thermoelectric characteristics of nanocrystalline ZnO grown on fabrics for wearable power generator. 597 Journal of Physics: Conference Series. IOP Publishing2018. p. 012017. 


\section{Declaration of interests}

$\bigotimes$ The authors declare that they have no known competing financial interests or personal relationships that could have appeared to influence the work reported in this paper.

$\square$ The authors declare the following financial interests/personal relationships which may be considered as potential competing interests:

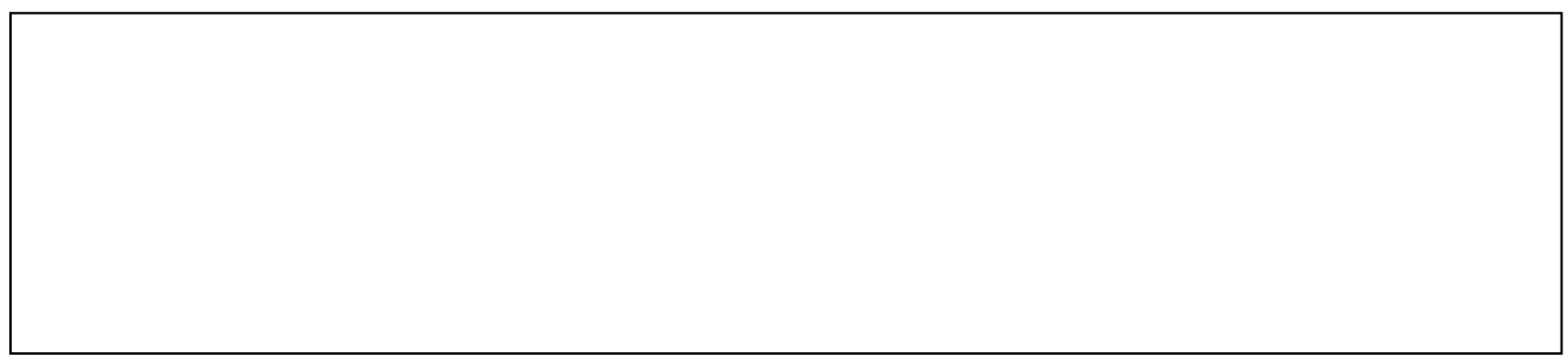

